\title{
ГОРНОДОБЫВАЮЩАЯ И МЕТАЛЛУРГИЧЕСКАЯ ПРОМЫШЛЕННОСТЬ ИОРДАНИИ: СОВРЕМЕННОЕ СОСТОЯНИЕ ПРОБЛЕМ И ПРИОРИТЕТЫ СТРАТЕГИЧЕСКОГО РАЗВИТИЯ
}

\author{
Аль Дарабсе А.М.Ф., \\ Маркова Е.B. \\ ИАТУ УлГТУ, г. Ульяновск, РФ
}

Устойчивый рост горнодобывающей $и$ металлургической промышленности и ее интеграчия в мировую экономику приобретает актуальность в контексте конкурентной позичии Иордании по запасам минерального сырья $u$ его производству. Цель исследования проанализировать текущее состояние горно-металлургического комплекса Иордании, выявить его проблемь и сформулировать стратегические приоритеты развития комплекса в современных условиях. В статье дан подробный анализ современного состояния крупных вертикально интегрированных компаний горно-металлургической отрасли Казахстана. Был сделан вывод, что интегрированные многонациональные компании $и$ отраслевые ассочиачии доказали свою эффективность на мировом рынке; более того, они внесли значительный вклад в экономику страны. SWOT-анализ горнодобывающей и металлургической промышленности показал, что основными проблемами и угрозами для развития национальной горнодобывающей промышленности являются внешние обстоятельства, глобальные тенденщии и внутренние условия. Определены перспективы развития горно-металлургической отрасли и основные стратегические предпосылки ее долгосрочного развития на внутреннем и внешнем рынках.

Ключевые слова: горнодобывающая, металлургическая промышленность, первичные металлы, SWOT-анализ, проблемы угроз, модернизация.

Разные сферы мировой экономики демонстрируют тенденцию консолидации и глобализации производства. Мировой опыт показывает, что единственный способ создания конкурентоспособных промышленных структур - это концентрация капитала и производственных мощностей и их вертикальная интеграция. Эта интеграция повышает эффективность производства за счет снижения операционных издержек и косвенного налогообложения промежуточных продуктов [1]. 
В конце двадцатого века в странах с рыночной экономикой наблюдался рост потребления стали и инновационная реструктуризация горнодобывающей промышленности. Это заложило основу для сокращения производственных мощностей в сталелитейном производстве и строительства новых компактных заводов по переработке готовой продукции с высокой добавленной стоимостью. Толчком к этому послужило желание промышленно развитых стран добиться более чистого производства. Это вызвало относительное снижение производства стали в развитых странах во второй половине двадцатого века и способствовало росту ее импорта из развивающихся стран [2].

Снижение доли металлургической промышленности в национальном выпуске развитых стран привело к росту металлургического производства в развивающихся странах. В развивающихся странах металлургическое производство строилось в основном на новой технологической основе [4]; он имел прогрессивную структуру производства и соответствовал мировым тенденциям развития [3].

В этом исследовании использовались теоретические, общенаучные и специальные методы [5]:

- историко-логические методы анализа современных тенденций развития металлургической отрасли Иордании;

- маркетинговый анализ, SWOT-анализ, в частности, для анализа конкурентных позиций, сильных и слабых сторон отечественной металлургической отрасли;

- качественные и количественные сравнения для анализа показателей, которые влияют на горнодобывающие и металлургические транснациональные компании, а также для определения степени влияния структурных факторов на инновации и конкурентоспособности горнодобывающих компаний;

- теоретическое моделирование и планирование для определения приоритетных направлений повышения конкурентоспособности горнодобывающих компаний в Иордании.

Методы экономико-статистического анализа были использованы для исследования текущего состояния металлургических компаний, определения тенденций и особенностей реструктуризации указанных компаний на современном этапе развития рыночной экономики в Иордании.

В этом исследовании использовался опыт других исследований, которые определили особенности реструктуризации компаний в развитых странах. Исследование было основано на статистических данных и аналитических отчетах международных организаций, таких как World Steel, World Coal, World Steel Dynamics, Eurofer, AISI, CISI, SEAISI, и агрегированных данных по горнодобывающей и металлургической промышленности Иордании [6].

Цель исследования - проанализировать текущее состояние горнодобывающей и металлургической промышленности Иордании, выявить ее проблемы и сформулировать стратегические приоритеты развития отрасли в современных условиях. 
Несмотря на последствия мирового экономического кризиса и упадок региональных рынков металлопродукции, выпуск новой высокотехнологичной продукции в мировой металлургической промышленности продолжается, причем основными инвесторами являются ведущие компании развитых стран.

Поэтому в среднесрочной перспективе место отечественной металлургии на региональных рынках металлопродукции будет зависеть от выбранной модели ее дальнейшего развития [7].

Глобальные тенденции могут объективно привести к значительному сокращению производства и экспорта готовой стали на основные региональные рынки, оставляя производство и экспорт только полуфабрикатов. В свою очередь, сокращение производства и экспорта металлопродукции может вызвать спад в развитии отечественной металлургической отрасли и стать одним из важнейших этапов экономического кризиса [8]. Это объективно сократит приток иностранной валюты, инвестиции в производство в смежные отрасли экономики, повысит уровень безработицы и ухудшит экономическую ситуацию в развитии населенных пунктов, где металлургическое производство имеет градообразующее значение [9].

В Иордании формирование современных горнодобывающих и металлургических корпораций происходило главным образом в 1993-1999 годах, то есть в условиях ухудшения производственных условий, вялой внешнеэкономической деятельности, нехватки инвестиций и других дестабилизирующих факторов. Изменения в производстве основных черных, драгоценных и цветных металлов в 2010-2014 гг. Свидетельствуют о том, что экономическая ситуация в горнодобывающей и металлургической промышленности в настоящее время стабильна [10].

В 2014 году добыча железной руды увеличилась на 2,7\%, хрома - на 6,3\%, рафинированного серебра - на 79,2\%, золота - на 99,3\%, необработанного свинца и цинка - на 22,9 и 1,9\% соответственно по сравнению с 2010 годом.

Добыча марганцевой руды за рассматриваемый период снизилась на $14,3 \%$, необработанного алюминия - на $12,8 \%$, а необработанной рафинированной меди - на $8,8 \%$.

Металлургия Иордании имеет уникальную сырьевую базу; Иордания это регион с сильно развитой цветной металлургией. По используемым технологиям, сложности сырья, качеству и количеству выпускаемой продукции основные компании цветной металлургии Иордании находятся на одном уровне с ведущими зарубежными аналогами [9].

Черноморские компании Иордании специализируются на производстве товарного железа и хрома, ферросплавов, готовой стали и черных металлов. В структуре этого подсектора доминируют производство черных металлов (более $60 \%$ ), добыча и обогащение сырой руды (около 25\%), а также производство ферросплавов [7].

По словам специалистов, 90 из 200 крупнейших компаний мира связаны с минеральными ресурсами. На их долю приходится $80 \%$ от общего объема реализованной продукции среди участников рейтинга. Тринадцать компаний 
Иордании являются одними из крупнейших производителей минеральных ресурсов для черной и цветной металлургии в мире [4].

В настоящее время АО «АрселорМиттал Темиртау» в основном производит следующие товары:

1. горячекатаная сталь в листах толщиной 1,6-12 мм и шириной 850-1524 MM;

2. холоднокатаная сталь в листах и рулонах толщиной $0,36-2,0$ мм и шириной 860-1400 мм;

3. олово, белое и черное, в листах и рулонах толщиной 0,20-0,36 мм;

4. холоднокатаная сталь с цинковым и алюминиево-цинковым покрытием толщиной 0,4-2,0 мм и шириной 750-1400 мм;

5. электросварные трубы;

6. рулонные плиты;

7. продукты химии кокса - сульфат аммония, нафталин, бензол, толуол, пек и др.

8. Торговый чугун;

9. Продукты переработки доменного шлака для цементной промышленности и дорожного строительства.

Анализируя научную и производственную деятельность компании, необходимо учитывать сложный минералогический и физико-химический состав используемого железного сырья. Это является причиной очень высокой по сравнению со смежными предприятиями удельной стоимости топливноматериальных ресурсов, что приводит к низким техническим и экономическим показателям, значительным выбросам в окружающую среду и большому объему твердых отходов.

Чтобы составить реальную аналитическую картину состояния и перспектив отечественной металлургической отрасли Иордании, необходимо использовать метод оценки сильных сторон (преимуществ), слабых сторон, возможностей и угроз, связанных с отраслью в целом. Предприятия используют SWOT-анализ для целей стратегического планирования и для оценки конкретных характеристик системы и ее среды [1].

Сильные стороны организации (сектора) подразумевают все, что дает ей преимущество перед конкурентами. Сильные стороны следующие: хорошая компетентность, достаточные финансовые ресурсы, совершенные технологии, хорошее управление, высокая этика труда, квалифицированная управленческая команда, высококачественная система контроля товаров и процессов и т. Д. Наиболее важные сильные стороны - это те, которые дают организации (сектор) долгосрочный отрыв от конкурентов, то есть то, что они не могут воспроизвести, или то, что связано с «исключительным превосходством» [6].

Слабые стороны организации (сектора) - вот что мешает ей иметь преимущество перед конкурентами. Недостатки заключаются в следующем: устаревшее оборудование, высокие производственные затраты, отсутствие четких стратегий развития, нехватка финансовых или других ресурсов, устаревшая организационная структура, плохое понимание рынка и т. д [4]. 
Сила MMI в Иордании заключается в собственной минерально-сырьевой базе и в том, что ее потенциал формировался десятилетиями, в течение которых была создана развитая инфраструктура и накоплен производственный и технологический опыт. $\mathrm{B}$ настоящее время это комплекс крупных производственных, горнодобывающих и обогатительных фабрик, рудников, металлургических заводов и площадок, исследовательских центров, институтов и лабораторий. Другая возможность проистекает из общих границ Иордании и стран с большими рынками. Другой сильной стороной является растущая технологическая потребность в металлах и металлопродукции [9].

Слабые стороны сектора связаны с низким качеством и низкой сложностью минерального сырья, высокой себестоимостью продукции ММІ изза низкой эффективности работы и энергоэффективности, плохим оборудованием производства с прогрессивными инновациями.

Еще один недостаток связан с отсутствием необходимых квалифицированных молодых кадров разного уровня и научно-технической специализации, предпенсионного и пенсионного возраста у большинства опытных горно-металлургических специалистов [8].

Серьезным недостатком ММI является его зависимость от импортных технологий и рынков внешней торговли, слабая связь между наукой и производством и транспортная инфраструктура, которая плохо адаптирована к структуре минерально-сырьевой базы [1].

Влияние недостатков может быть заметно уменьшено посредством законодательного и правового обеспечения обновления активной части основных производственных фондов, диверсификации производства в направлении получения готовой продукции с высокой добавленной стоимостью, интенсификации современных научно-технических разработок и принятия мер для стимулирование притока молодых специалистов. Проблемы и угрозы развитию отечественной горно-металлургической отрасли обусловлены внешними обстоятельствами, мировыми тенденциями и внутренними обстоятельствами [4].

Серьезной проблемой развития МMI является сокращение выпуска продукции из-за устаревших активов, несоответствия технологий и оборудования предприятий по переработке сложных руд. Научная, технологическая и техническая задержка, вызванная недостаточным финансированием НИОКР в последние годы [1]. Это приводит к значительным потерям основного и сопутствующего продукта на стадии обогащения и конверсии металла, что приводит к накоплению металла в хвостах мельниц, шлаках, клинкере, фильтрационной корке, мелочи и других промежуточных продуктах. Это истощает запасы незаменимых минералов и оказывает негативное влияние на окружающую среду [9].

Главная угроза исходит от того, что Иордания ВТО в сложившейся ситуации может стать сырьевым «придатком» для мировой экономики вторичного сырья. Кроме того, мировой финансовый кризис может вызвать резкое падение цен на различные металлы и металлопродукцию. 
Ряд факторов могут формировать внутренние проблемы и угрозы:

1. не обнаружение новых конкурентоспособных месторождений цинка, меди и свинца в течение 5-10 лет;

2. критическая задержка осознания обществом и органами государственной власти необходимости принятия осторожных шагов в направлении перехода к стратегическому государственному регулированию отрасли;

3. неполная и непоследовательная открытая достоверная информация об отрасли при принятии радикальных решений;

4. потеря приобретенных знаний и технологического опыта старших специалистов.

Одним из основных условий устойчивого развития высокотехнологичного горнопромышленного комплекса должна быть интегрированная роль всех его компонентов с точки зрения целей и задач.

В отличие от других развитых и развивающихся стран, Иордания не строила технологически новые предприятия в металлургическом секторе. Компании просто проводили выборочную модернизацию, нацеленную не столько на совершенствование прокатного производства и производственного комплекса, а на высококачественную готовую сталь, сколько на замену устаревшего оборудования для сокращения сырьевых и энергетических компонентов в структуре себестоимости продукции [9]. При этом модернизация основана на отечественном оборудовании и отечественных технологических изобретениях, которые, несмотря на относительно низкие затраты, менее эффективны по сравнению с зарубежными аналогами [7].

Это привело к тому, что большинство отечественных горнодобывающих и металлургических компаний имели значительно устаревшее оборудование (50$85 \%$ ), низкую эффективность работы, высокий уровень материалоемкости и энергопотребления производства, а также широко использовали мартеновское производство стали, которое практически нигде не используется Мир [9].

Несмотря на устаревшую технологическую и техническую инфраструктуру, продукция отечественных экспортеров является конкурентоспособной (при определенных конкурентных преимуществах ее качество сопоставимо с аналогичной продукцией ведущих мировых экспортеров) и продается на различных рынках.

Основной тенденцией на зарубежном металлургическом рынке является консолидация, которая всегда придерживалась рыночных законов: производятся слияния, поглощения и альянсы с целью сокращения расходов в масштабе, близости к рынкам сбыта или источникам сырья. Анализ показал, что в Казахстане также наблюдается значительная консолидация активов в металлургическом комплексе. При этом процесс консолидации и интеграции сам по себе является не целью, а всего лишь инструментом.

Чтобы сохранить конкурентные преимущества металлургического комплекса Иордании и связанное с этим расширение внутреннего и внешнего рынков, важно переоборудовать и реконструировать устаревшие мощности, 
сократить все виды затрат на производство и внедрить комплексные технологии ресурсосбережения и энергосбережения. Концентрация капитала нужна точно.

Вклад этого исследования в мировую науку - это всестороннее исследование деятельности горнодобывающей и горнодобывающей промышленности в стране в контексте долгосрочных приоритетов развития и выявление проблем, которые препятствуют этому развитию. Частный вклад в практику заключается в продвинутых рекомендациях, связанных с развитием горнодобывающей и горнодобывающей промышленности в Иордании в современных условиях [6].

В статье приводится подробный анализ современного состояния вертикально интегрированных крупных компаний в горнодобывающей и горнодобывающей промышленности Иордании. Он пришел к выводу, что многочисленные интегрированные промышленные компании и ассоциации доказали свою эффективность на мировом рынке, а также внесли значительный вклад в экономику страны. SWOT-анализ был использован для определения текущего состояния горнодобывающей и горнодобывающей промышленности страны. Он показал, что основные проблемы и угрозы развитию национальной горнодобывающей промышленности исходят из внешних условий, глобальных тенденций и внутренних условий. Определены перспективы развития горнодобывающей и горнодобывающей промышленности и определены ключевые стратегические предпосылки еe долгосрочного развития на внутреннем и внешнем рынках.

Было установлено, что для сохранения конкурентных преимуществ Иорданского минерального комплекса и связанной с этим экспансии на внутреннем и внешнем рынках важно переоборудовать и реконструировать старые объекты, сократить все виды производственных затрат и использовать ресурсы и энергию. Предоставлять технологии комплексным способом.

Концентрация капитала чрезвычайно важна для достижения целей. Основные стратегические направления повышения эффективности горнодобывающей промышленности в Иордании указывают на изменение доли «экспортного потребления» в сторону увеличения внутреннего потребления, внедрения унификации рынка, анализа целесообразности создания вертикально интегрированных рыночных структур, развития технической и технологической базы и внедрения новых технологий для переработки сырья.

\section{Список литературы}

1. Миллер В.В. Роль искусственного интеллекта в роботехнике. // В сборнике: Биотехнические, медицинские и экологические системы, измерительные устройства и робототехнические комплексы - Биомедсистемы2019 Сборник трудов XXXII Всероссийская научно-техническая конференция студентов, молодых ученых и специалистов. Под общей редакцией В.И. Жулева. 2019. С. 638-641. 
2. Аль-Дарабсе А.М.Ф. Проблемы программного обеспечения в авиационных системах. // В сборнике: Проблемы технического сервиса в АПК Сборник научных трудов II студенческой всероссийской научно-практической конференции. 2019. С. 7-15.

3. Вольсков Д.Г. Подрыв конфиденциальности в системе адресации отчетности авиационной связи. // В сборнике: Миллионщиков-2019 Материалы II Всероссийской научно-практической конференции студентов, аспирантов и молодых ученых, посвященной 100-летию ГГНТУ. 2019. С. 123-129.

4. Маркова Е.В. Система мониторинга работособности авиационных газотурбинных двигателей по реальным данным. // В сборнике: Миллионщиков-2019 Материалы II Всероссийской научно-практической конференции студентов, аспирантов и молодых ученых, посвященной 100летию ГГНТУ. 2019. С. 137-143.

5. Маркова Е.В. Особенности снабжения аэрокосмической промышленности. // В сборнике: В мире научных открытий Материалы III Международной студенческой научной конференции. 2019. С. 137-140.

6. Черненькая Е.В. Форсайт-аудит систем управления в аэрокосмической технологии. // Вестник Ульяновского государственного технического университета. 2019. № 1 (85). С. 71-73.

7. Маркова Е.В., Аль-Дарабсе А.М.Ф. Влияние инноваций на экономический рост. // Вестник Ульяновского государственного технического университета. 2019. № 2 (86). С. 72-74.

8. Аль-дарабсе А.М.Ф., Маркова Е.В. Исследование требований летной годности составных воздушных судов для воздушных судов транспортной категории в FAA. // Российский электронный научный журнал. 2019. № 1 (31). C. 8-21.

9. Денисова Т.В. Моделирование турбовинтовой гибридной электрической двигательной установки. // Российский электронный научный журнал. 2019. № 2 (32). С. 16-33.

10. Черненькая Е.В. Исследование экономических систем в авиастроении на основе методологии функционально-стоимостной инженерии. // В сборнике: Молодежь и наука XXI века Материалы Международной научной конференции. 2018. С. 470-472. 